Check for updates

Cite this: RSC Adv., 2019, 9, 16919

Received 19th April 2019 Accepted 23rd May 2019

DOI: 10.1039/c9ra02937k

rsc.li/rsc-advances

\section{Preparation of two different crystal structures of cerous phosphate as solid acid catalysts: their different catalytic performance in the aldol condensation reaction between furfural and acetone $\uparrow$}

\author{
Wenzhi Li, (D) a Mingxue Su, (DD *a Tao Yang, ${ }^{\text {a }}$ Tingwei Zhang, (D) a Qiaozhi Ma, ${ }^{\text {b }}$ Song Li \\ and Qifu Huang (D)
}

Liquid fuel intermediates can be produced via aldol condensation reactions through furan aldehydes and ketones driven from biomass. It was found that cerous phosphate (CP) with two different crystal structures (hexagonal and monoclinic structure), which was tailored by different hydrothermal temperature $\left(120^{\circ} \mathrm{C}\right.$ for the hexagonal structure and $180{ }^{\circ} \mathrm{C}$ for the monoclinic structure) and calcination temperature $\left(900^{\circ} \mathrm{C}\right.$ for the monoclinic structure) as a solid acid catalyst, exhibit high catalytic performance in aldol condensation between furfural and acetone. The CP with hexagonal structure gave $89.1 \%$ conversion of furfural with $42 \%$ yield of 4-(2-furyl)-3-buten-2-one (FAc) and 17.5\% of yield of 1,5-di-2-furanyl-1,4pentadien-3-one $\left(\mathrm{F}_{2} \mathrm{Ac}\right)$, much higher than $\mathrm{CP}$ with monoclinic structure. However, both furfural conversion and aldol product yield increased from $82.3 \%$ to $96 \%$ and from $50.5 \%$ to $68.4 \%$, respectively, for $\mathrm{CP}$ with the monoclinic structure after calcination owing to the higher amount of acid of catalyst after calcination but decreased continuously for CP with hexagonal structure after calcination because of its rapidly reduced BET surface area and total pore volume. The results indicated that calcination affects significantly the physical-chemical properties of CP catalysts, which influence subsequently the catalytic performance in the aldol condensation reaction. Recycling experiments showed that the catalytic performance after five number runs for $\mathrm{CP}$ with monoclinic structure after calcination was acceptable but was not ideal for CP with hexagonal structure owing to its poor hydrothermal stability.

\section{Introduction}

The manufacture of liquid fuel from sustainable resources has caused widespread concern because of environmental pollution. Although there are many renewable resources, lignocellulosic biomass is the only carbon-neutral, renewable and abundant energy resource and has been widely applied to produce biofuels through several consecutive steps. ${ }^{1-5}$ In general, polysaccharide in lignocellulose can be hydrolyzed into monosaccharide and these constituent sugar monomers can be further hydrolyzed into furfural and 5-hydroxymethylfurfural (HMF), two important

\footnotetext{
${ }^{a}$ Laboratory of Basic Research in Biomass Conversion and Utilization, Department of Thermal Science and Energy Engineering, University of Science and Technology of China, Hefei 230026, China.E-mail: smx123@mail.ustc.edu.cn

${ }^{b}$ College of Materials and Energy, South China Agricultural University, Guangzhou 510642, China

${ }^{c}$ CAS Key Laboratory of Renewable Energy, Guangzhou Institute of Energy Conversion, Chinese Academy of Sciences, Guangzhou 510640, China

${ }^{d}$ Beijing Mechanical Equipment Institute, Beijing, 100854, P. R. China

$\dagger$ Electronic supplementary information (ESI) available. See DOI: 10.1039/c9ra02937k
}

furanic platform chemicals, by homogeneous or heterogeneous acid catalysts. ${ }^{6-8}$ There were two main methods to produce liquid fuel from the furfurals: production of linear C5-C6 alkane via direct hydrodeoxygenation of furfurals and manufacture of C7C15 alkane with high octane number values by continuous steps consisting of sequential aldol condensation and hydrodeoxygenation., ${ }^{\mathbf{9} 10}$ Through these pathways, biomass feedstock can be transformed into high value-added aviation kerosene.

Aldol condensation reaction was considered as a key step to produce liquid fuels from lignocellulose since low carbon molecules like furfural can be transformed into high carbon chain precursors. For example, C8-C13 liquid fuel precursors can be formed through aldol condensation between furfural and acetone. ${ }^{11}$ There were many types of catalysts applied to catalyze this aldol condensation reaction of furfural and acetone. Initially, several homogeneous base catalysts, such as $\mathrm{Ca}(\mathrm{OH})_{2}$ and $\mathrm{NaOH}$, were used to this aldol condensation reaction pathway. ${ }^{12-17} \mathrm{VCl}_{3}$ and other metal chloride were also used as catalysts. ${ }^{18}$ However, corrosion, enhancing selfcondensation, non-recyclability, high cost and high expense of neutralizing generated waste water stream were unavoidable 
drawback of these homogeneous catalysts. ${ }^{19}$ To overcome these defect, stable heterogeneous catalysts were designed and developed. It was reported that mixed metal oxides like $\mathrm{Mg}-\mathrm{Al}$, $\mathrm{Mg}-\mathrm{Zr}$, Ca-Zr mixed oxides, natural dolomitic rocks and anionexchange resins were all active to aldol condensation reaction between furfural and acetone..$^{\mathbf{2 0}-27}$ For example, Huber et al. study the catalytic characteristics of $\mathrm{Mg}-\mathrm{Zr}$ mixed oxide in a methanol-water biphasic system and a 54\% yield of aldol products was achieved. ${ }^{28}$ In addition, zeolite was also applied to catalyze aldol condensation reaction. For example, Yuriy et al. study the cross-aldol condensation reaction of aromatic aldehydes and acetone using Lewis acid zeolites such as Sn-, Hf- and Zr-beta with high conversion and selectivity under mild condition. ${ }^{29-33}$ Additionally, Li et al. used Sn-MFI zeolite as catalyst and achieved shape selectivity to mono product. $^{34}$ These researches indicated the development of stable heterogeneous catalysts, which was applied to aldol condensation reaction of furfural and acetone, was necessary and successful.

Recently, cerium phosphate has caused extensive attention because it was widely applied to the assembly of electrochemical, electrical and optical nanodevices. In addition, cerium phosphate was also widely used as a catalyst or catalyst carrier in selective reduction of NOx, CO oxidation, $n$-butane oxidation and hydrogenation and exhibited good catalytic performance. ${ }^{35-44}$ In particular, Michikazu et al. reported that cerium phosphate may act as a bifunctional catalyst with both Lewis acid and weak base sites, which was used to chemoselective acetalization of 5-hydroxymethylfurfural with alcohols and exhibited high catalytic performance. ${ }^{45}$ Additionally, Wang et al. reported cerium phosphate can be used as solid Lewis acid catalyst for dehydration of glucose into 5-hydroxymethylfurfural (HMF) and achieved 61\% yield of 5-hydroxymethylfurfural (HMF) with $97 \%$ conversion of glucose. ${ }^{46}$ These researches highlighted that cerium phosphate be a multifunctional material and potential to catalyze some reactions that required an acid catalyst, such as aldol condensation reaction.

The physical-chemical properties of cerium phosphate can be significantly affected by the different crystal structure of cerium phosphate, which further play an important influence in catalytic performance of cerium phosphate. However, the differences of catalytic behavior due to different crystal structures of cerium phosphate was not reported in aldol condensation reaction to the best of our knowledge. Herein, two different crystal structure of cerium phosphate was synthesized and the different changes of physical-chemical properties of cerium phosphate after heat treatment was studied. In addition, cerium phosphate was used as a solid acid catalyst to catalyze aldol condensation reaction of furfural and acetone. The effects of calcination temperature of catalysts on catalytic activity was systematic studied. Reaction time, reaction temperature and reusability were also studied.

\section{Experimental}

\section{Materials preparation}

Furfural (AR, 99\%) was purchased from Aladdin Industrial. Inc. (Shanghai, China), cerium(III) nitrate hexahydrate
$\left(\mathrm{Ce}\left(\mathrm{NO}_{3}\right)_{3} \cdot 6 \mathrm{H}_{2} \mathrm{O}\right)$, ammonium dihydrogen phosphate $\left(\mathrm{NH}_{4} \mathrm{H}_{2} \mathrm{PO}_{4}\right)$, cerium oxide (AR) and acetone (AR) were purchased from Sinopharm Chemical Reagent Co. Ltd (Shanghai, China). All reagents were used without any purification.

\section{Catalyst preparation}

The cerium phosphate catalyst (CP) with monoclinic structure was synthesized by modified method according to previous literature. ${ }^{45}$ Typically, $\mathrm{Ce}\left(\mathrm{NO}_{3}\right)_{3} \cdot 6 \mathrm{H}_{2} \mathrm{O}(6 \mathrm{mmol}, 2.6 \mathrm{~g})$ and $\mathrm{NH}_{4} \mathrm{H}_{2} \mathrm{PO}_{4}$ (6 mmol, $0.69 \mathrm{~g}$ ) were dissolved in $70 \mathrm{ml}$ DI water under stirring for $1 \mathrm{~h}$ at room temperature. The obtained solution was transferred into a $100 \mathrm{ml}$ Teflon-lined stainless autoclave and heated at $180{ }^{\circ} \mathrm{C}$ for 4 days. The formed precipitates were collected by centrifugation and washed thoroughly with DI water. After dried at $80{ }^{\circ} \mathrm{C}$ overnight, the solid product was calcined at $500{ }^{\circ} \mathrm{C}, 700{ }^{\circ} \mathrm{C}$ and $900{ }^{\circ} \mathrm{C}$ for $3 \mathrm{~h}$. The obtained catalysts were named as CP-180-500, CP-180-700 and CP-180-900. Particularly, the catalyst without calcination was donated as CP-180-0.

The cerium phosphate catalyst (CP) with hexagonal structure was synthesized by modified method according to previous literature. ${ }^{46}$ Typically, $\mathrm{Ce}\left(\mathrm{NO}_{3}\right)_{3} \cdot 6 \mathrm{H}_{2} \mathrm{O}(6 \mathrm{mmol}, 2.6 \mathrm{~g})$ and $\mathrm{NH}_{4} \mathrm{H}_{2} \mathrm{PO}_{4}$ (6 mmol, $0.69 \mathrm{~g}$ ) were dissolved in $70 \mathrm{ml}$ DI water under stirring for $1 \mathrm{~h}$ at room temperature. The obtained solution was transferred into a $100 \mathrm{ml}$ Teflon-lined stainless autoclave and heated at $120{ }^{\circ} \mathrm{C}$ for $8 \mathrm{~h}$. The formed precipitates were collected by centrifugation and washed thoroughly with DI water. After dried at $80^{\circ} \mathrm{C}$ overnight, the solid product was calcined at $500{ }^{\circ} \mathrm{C}$, $700{ }^{\circ} \mathrm{C}$ and $900{ }^{\circ} \mathrm{C}$ for $3 \mathrm{~h}$. The obtained catalysts were named as CP-120-500, CP-120-700 and CP-120-900. Particularly, the catalyst without calcination was donated as CP-120-0.

For comparison, phosphorus doped $\mathrm{CeO}_{2}$ was synthesized by impregnation method. Typically, $\mathrm{NH}_{4} \mathrm{H}_{2} \mathrm{PO}_{4}$ was firstly dissolved in $70 \mathrm{ml}$ DI water under stirring and then $\mathrm{CeO}_{2}$ was put into the solution. The water was evaporated at $80{ }^{\circ} \mathrm{C}$ and the remaining mixture was dried at $100{ }^{\circ} \mathrm{C}$ overnight. The obtained solid powder was calcined at $500{ }^{\circ} \mathrm{C}$ for $5 \mathrm{~h}$. The obtained powder was named as $\mathrm{P} / \mathrm{CeO}_{2}$.

\section{Catalyst characterization}

Powder X-ray diffraction (XRD) patterns of CP catalysts were recorded by a Smartlab X-ray diffractometer equipped with a $\mathrm{Cu}-\mathrm{K} \alpha$ radiation source. Fourier transform infrared spectroscopy (FTIR) of CP catalysts were measured by ThermoFisher Nicolet IS200, using KBr disks. SEM images of CP catalysts were characterized by ZEISS GeminiSEM 500 scanning electron microscope. The textural properties of CP catalysts were measured by an Autosorbi Q (Quantachrome). The ammonia gas temperature programmed desorption $\left(\mathrm{NH}_{3}-\mathrm{TPD}\right)$ were analyzed by ChemStar TPx chemisorption analyzer (Quantachrome Instrument).

\section{Catalytic reaction and analysis methods}

Aldol condensation reaction of furfural and acetone was performed in a Synthware thick-walled pressure bottle. In a typical reaction, $0.12 \mathrm{~g}$ furfural and $0.71 \mathrm{~g}$ acetone (the molar ratio of 
furfural/acetone $=1 / 10$ ) were mixed in this glass reactor with $0.1 \mathrm{~g}$ catalyst. Afterwards, the reactor was put into oil bath preheated at $100{ }^{\circ} \mathrm{C}, 120{ }^{\circ} \mathrm{C}, 140{ }^{\circ} \mathrm{C}$, and $160{ }^{\circ} \mathrm{C}$ under $0-4 \mathrm{~h}$. After reaction, the reactor was fast cool down using an ice bath, followed by centrifugation to separate the catalyst. Finally, the remaining solution was transferred into a GC vial and analyzed by using Shimadzu GC-2010 equipped with FID.

The catalytic performance was evaluated by furfural conversion, FAc yield and $F_{2}$ Ac yield. The formula was defined as follow: ${ }^{28}$

$$
\begin{gathered}
\text { Furfural conversion }(\%)=\frac{\text { moles of furfural reacted }}{\text { moles of furfural started }} \times 100 \\
\text { FAc yield }(\%)=\frac{\text { moles of FAc }}{\text { moles of furfural started }} \times 100 \\
\mathrm{~F}_{2} \text { Ac yield }(\%)=\frac{\text { moles of } \mathrm{F}_{2} \text { Ac }}{\text { moles of furfural started }} \times 100
\end{gathered}
$$

\section{Results and discussion}

The XRD patterns of prepared $\mathrm{P} / \mathrm{CeO}_{2}, \mathrm{CP}-120-0, \mathrm{CP}-180-0$ and pure $\mathrm{CeO}_{2}$ (purchased) was depicted in Fig. 1. For the $\mathrm{P} / \mathrm{CeO}_{2}$ sample, compared with pure $\mathrm{CeO}_{2}$, a few new diffraction peaks consistent with some of characteristic peaks of cerium phosphate was obtained, indicating some cerium phosphate phases was formed through impregnation method. ${ }^{37}$ For the CP-120-0 and CP-180-0 samples, diffraction peaks were completely different from pure $\mathrm{CeO}_{2}$ and highly corresponding with the main diffraction peaks of cerium phosphate phase, which was different with $\mathrm{P} / \mathrm{CeO}_{2}$ sample, indicating cerium phosphate catalysts were formed successfully through hydrothermal method. ${ }^{45,46}$

Fig. 2 and 3 showed the XRD patterns of CP catalysts prepared by hydrothermal method at $120{ }^{\circ} \mathrm{C}$ and $180{ }^{\circ} \mathrm{C}$ and followed by calcination at $500{ }^{\circ} \mathrm{C}, 700{ }^{\circ} \mathrm{C}$ and $900{ }^{\circ} \mathrm{C}$,

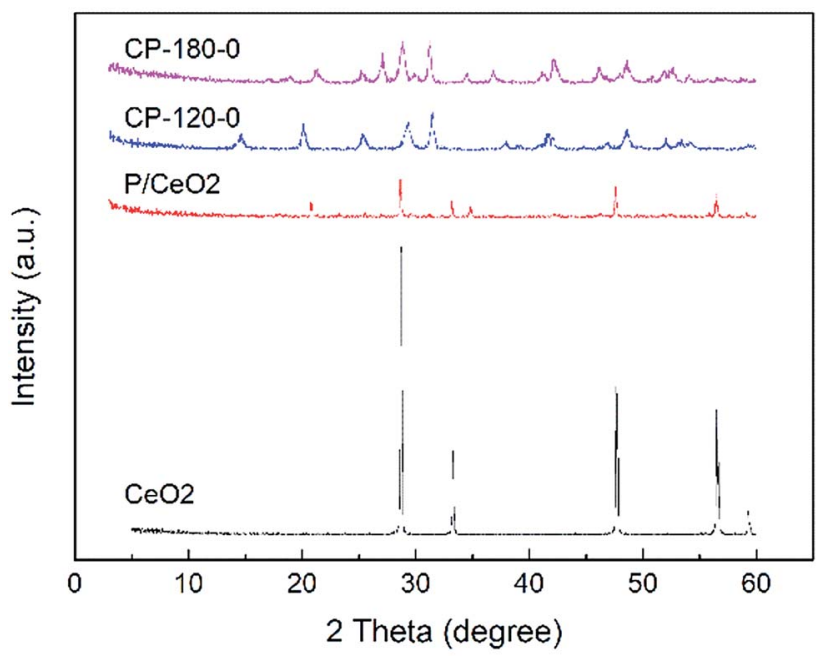

Fig. 1 The XRD patterns of $\mathrm{CeO}_{2}, \mathrm{P} / \mathrm{CeO}_{2}, \mathrm{CP}-120-0$ and $\mathrm{CP}-180-0$.

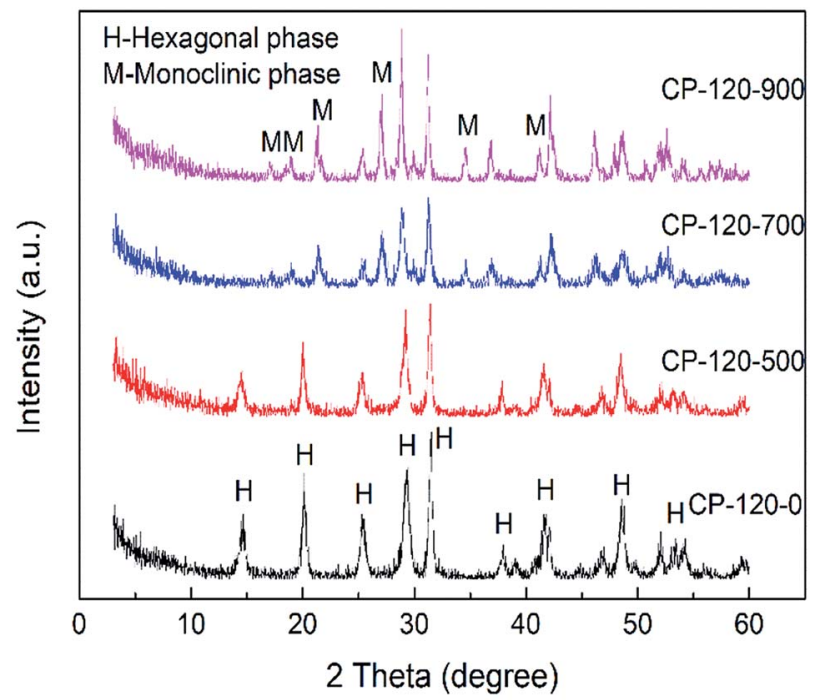

Fig. 2 The XRD patterns of CP catalysts prepared by hydrothermal method at $120^{\circ} \mathrm{C}$ and followed by calcination at different temperature.

respectively. As shown in Fig. 2, for the CP-120-0 sample, the characteristic peaks at 2 theta of 14.4, 20.1, 25.3, 29.2 , 31.5, 37.7, $41.9,48.2$ and $53.3^{\circ}$ were attributed to the hexagonal structure of cerium phosphate. However, after calcination at $500{ }^{\circ} \mathrm{C}$, the intensity of the diffraction peaks at 14.4 and $20.1^{\circ}$, corresponding with (100) and (101) crystal planes of hexagonal structure of cerium phosphate, respectively, decreased. With the calcination temperature was increased to $700{ }^{\circ} \mathrm{C}$, the diffraction peaks at 14.4 and $20.1^{\circ}$ completely disappeared, which indicated the hexagonal structure of cerium phosphate was destroyed after heat treatment. In the meanwhile, some new characteristic peaks at 2 theta of 17.0, 19.0, 21.3, 27.1, 34.5 and $41.2^{\circ}$, which were ascribed to (101), (011), (111), (200), (202) and (103) of crystal planes of monoclinic structure of cerium phosphate, were obtained and appeared completely after calcination at $900{ }^{\circ} \mathrm{C}$ further. ${ }^{46}$ These results reveal that cerium phosphate with hexagonal structure was unstable and the

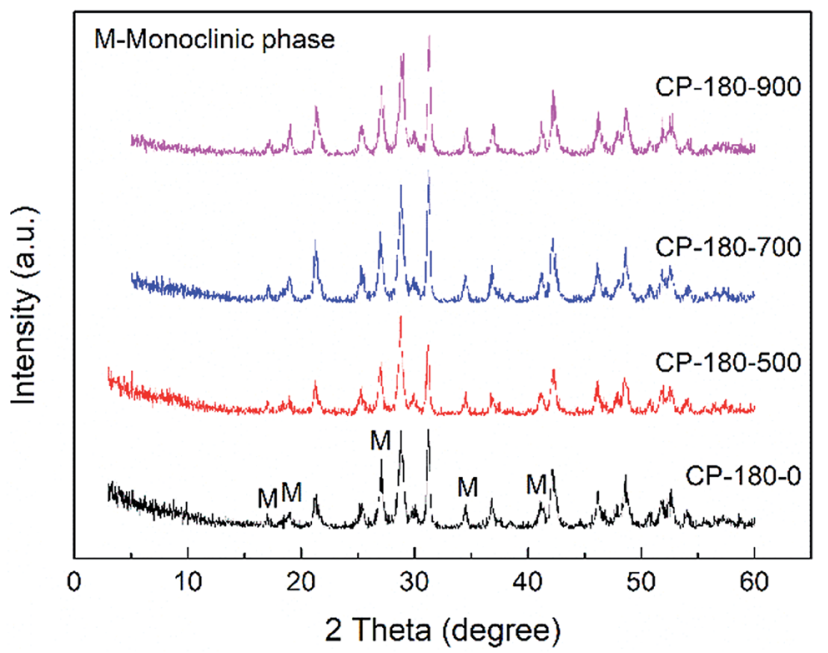

Fig. 3 The XRD patterns of CP catalysts prepared by hydrothermal method at $180^{\circ} \mathrm{C}$ and followed by calcination at different temperature. 
transformation of crystal structure from hexagonal structure to monoclinic structure was achieved after calcination at $900{ }^{\circ} \mathrm{C}$.

As shown in Fig. 3, for the CP-180-0 sample, the diffraction peaks at 2 theta of $17.0,19.0,21.3,27.1,34.5$ and $41.2^{\circ}$ were observed, revealing the cerium phosphate prepared by hydrothermal method at $180{ }^{\circ} \mathrm{C}$ was monoclinic structure. ${ }^{46}$ With the calcination temperature was continuously increased to $900{ }^{\circ} \mathrm{C}$, these characteristic peaks did not change significantly, suggesting the cerium phosphate with monoclinic structure was stable and the monoclinic structure was still remained even after calcination at $900{ }^{\circ} \mathrm{C}$.

Fig. 4 and 5 displayed the FTIR results of CP catalysts prepared by hydrothermal method at $120{ }^{\circ} \mathrm{C}$ (hexagonal

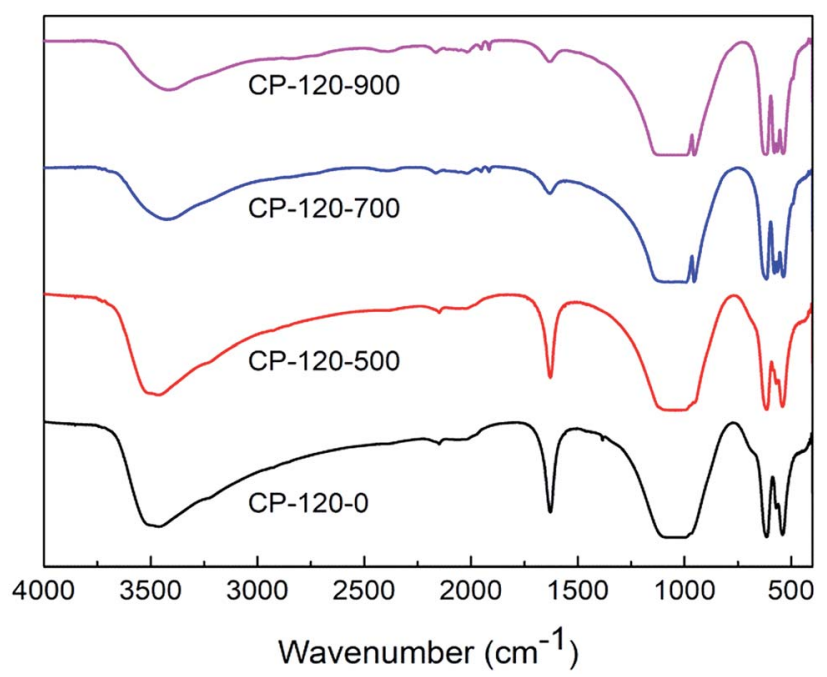

Fig. 4 The FTIR spectra of CP catalysts prepared by hydrothermal method at $120^{\circ} \mathrm{C}$ (hexagonal structure) and followed by calcination at different temperature.

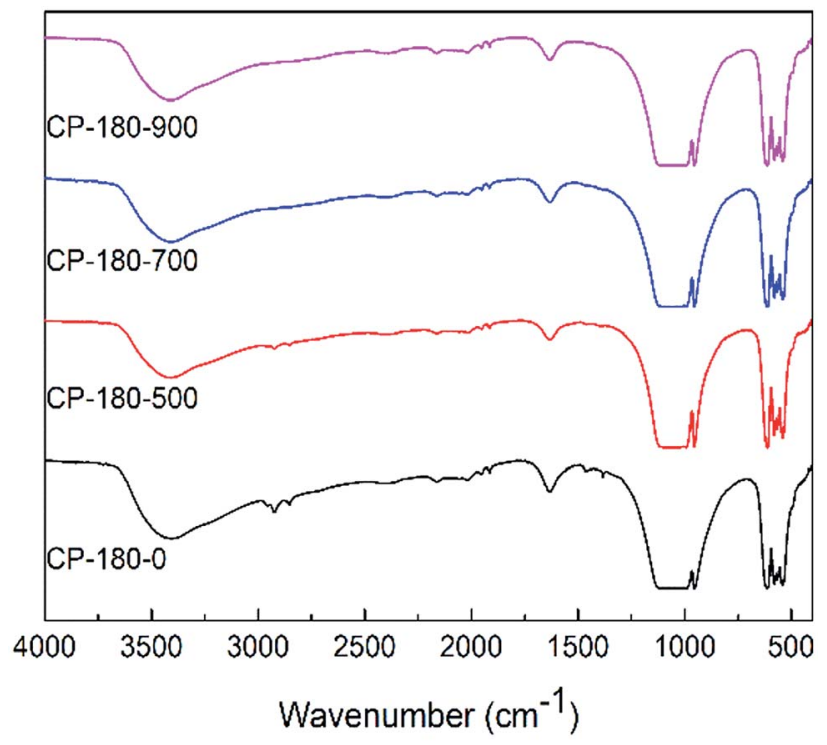

Fig. 5 The FTIR spectra of CP catalysts prepared by hydrothermal method at $180^{\circ} \mathrm{C}$ (monoclinic structure) and followed by calcination at different temperature. structure) and $180{ }^{\circ} \mathrm{C}$ (monoclinic structure) and followed by calcination at $500{ }^{\circ} \mathrm{C}, 700{ }^{\circ} \mathrm{C}$ and $900{ }^{\circ} \mathrm{C}$, respectively. As shown in Fig. 4, for the cerium phosphate with hexagonal structure without calcination sample (CP-120-0), a broad absorption band around $3500 \mathrm{~cm}^{-1}$ was ascribed to $-\mathrm{OH}$ absorption. Likewise, the band around $1625 \mathrm{~cm}^{-1}$ can be possible attributed to hydration water of $\mathrm{CePO}_{4} \cdot n \mathrm{H}_{2} \mathrm{O} .{ }^{47} \mathrm{~A}$ broad adsorption band around $1064 \mathrm{~cm}^{-1}$ was observed, which was ascribed to $\mathrm{P}=\mathrm{O}$ stretching mode. ${ }^{48}$ The band around $620 \mathrm{~cm}^{-1}$ and $535 \mathrm{~cm}^{-1}$ were $\mathrm{O}=\mathrm{P}-\mathrm{O}$ bending vibration and $\mathrm{Ce}-\mathrm{O}$ stretching vibration. ${ }^{47,48}$ However, with the increase of calcination temperature, the broad adsorption band around $1625 \mathrm{~cm}^{-1}$ was gradually weak, implying the loss of hydration water, and two new adsorption band around $945 \mathrm{~cm}^{-1}$ and $575 \mathrm{~cm}^{-1}$, which were ascribed to asymmetric stretching vibration of phosphate groups and $\mathrm{O}-\mathrm{P}-\mathrm{O}$ bending vibration, respectively, appeared. ${ }^{\mathbf{4 8}}$ These results implied the change of cerium phosphate with hexagonal structure occurred after calcination and was probably ascribed to the transformation of crystal structure according to XRD results.

However, for cerium phosphate prepared by hydrothermal method at $180{ }^{\circ} \mathrm{C}$ (monoclinic structure) with or without calcination, there were no obvious difference in FTIR results, as shown in Fig. 5. These results implied cerium phosphate with monoclinic structure was stable during calcination, which was corresponding to XRD results. Particularly, the FTIR curves of all CP-180 samples were similar to CP-120-900 sample, which may be owing to the same crystal structure (monoclinic structure) of these catalysts.

The morphology of CP catalysts with hexagonal and monoclinic structure before/after calcination (CP-120-0, CP-120-900, CP-180-0 and CP-180-900) was studied by SEM and results were shown in Fig. 6. It can be clearly seen that CP-120-0 catalyst display a fine rod-like shaped particles (Fig. 6A). However, CP120-900 displayed a rougher rod-like morphology compared with CP-120-0, which was attributed to agglomeration among particles after calcination (Fig. 6B). Fig. 6C and D showed there

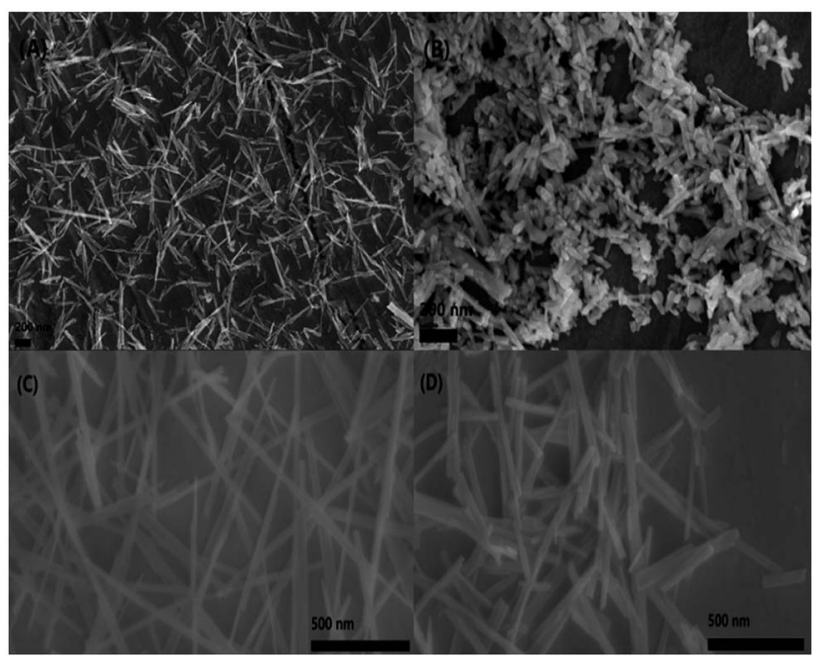

Fig. 6 The SEM images of CP-120-0 (A), CP-120-900 (B), CP-1800 (C) and CP-180-900 (D). 
were no significantly difference between CP-180-0 and CP-180900 , respectively, and both two catalysts display a fine rod-like morphology.

The textural properties of CP catalysts with hexagonal and monoclinic structure before/after calcination (CP-120-0, CP-120900, CP-180-0 and CP-180-900) driven from $\mathrm{N}_{2}$ adsorptiondesorption isotherms at $77 \mathrm{~K}$ were summarized in Table 1. It can be seen that cerium phosphate with hexagonal structure catalyst (CP-120-0) had the highest BET surface area and largest total pore volume, $55.7 \mathrm{~m}^{2} \mathrm{~g}^{-1}$ and $0.44 \mathrm{~cm}^{3} \mathrm{~g}^{-1}$, respectively, compared with cerium phosphate with monoclinic structure catalyst (CP-180-0), $46.7 \mathrm{~m}^{2} \mathrm{~g}^{-1}$ and $0.30 \mathrm{~cm}^{3} \mathrm{~g}^{-1}$, respectively. However, the BET surface area and total pore volume of CP catalysts with hexagonal structure after calcination at $900{ }^{\circ} \mathrm{C}$ (CP-120-900) were drastically reduced to $24.9 \mathrm{~m}^{2} \mathrm{~g}^{-1}$ and 0.25 $\mathrm{cm}^{3} \mathrm{~g}^{-1}$, respectively. This reduction was chiefly caused by agglomeration or structural collapse of hexagonal structure catalyst after calcination. Conversely, for CP-180-900 sample, the BET surface area and total pore volume were $42.9 \mathrm{~m}^{2} \mathrm{~g}^{-1}$ and $0.28 \mathrm{~cm}^{3} \mathrm{~g}^{-1}$, respectively, slightly lower than CP-180-0, but higher than CP-120-900. These results implied that the textural properties of CP catalyst with monoclinic structure were more stable than hexagonal structure during calcination.

The acidic properties of CP catalysts with hexagonal and monoclinic structure before/after calcination (CP-120-0, CP-120900, CP-180-0 and CP-180-900) were determined by $\mathrm{NH}_{3}$-TPD and results were displayed in Fig. 7 and Table 2. As shown in Fig. 7, the CP-120-0 catalyst exhibited a broad desorption peaks at around $250{ }^{\circ} \mathrm{C}$, which was ascribed to weak $\mathrm{NH}_{3}$ adsorption. This result demonstrated that a weak acid site exist in CP-1200 catalyst. It was worth noting that the position of desorption peak for catalyst after calcination (CP-120-900) shifted to the lower temperature, around $160{ }^{\circ} \mathrm{C}$, which was assigned to weaker acid site of catalyst after calcination, and the desorption peak strengthened, which was attributed to higher amount of acid of catalyst after calcination. For the CP-180-0 catalyst, a broad desorption appeared at around $200{ }^{\circ} \mathrm{C}$. After calcination, the peak area also increased, implying the amount of acid increased, but the peak position did not change obviously (CP180-900). These results clearly demonstrated calcination significantly affect the acidic properties of CP catalysts with two different structures. Differently, calcination only affect the amount of acid for monoclinic structure but not only amount of acid but also acid strength for hexagonal structure. The quantitative data of $\mathrm{NH}_{3}$-TPD for CP catalysts were summarized in

Table 1 The textural properties of CP-120-0, CP-120-900, CP-1800 and CP-180-900

\begin{tabular}{lll}
\hline Catalysts & BET surface area ${ }^{a}\left(\mathrm{~m}^{2} \mathrm{~g}^{-1}\right)$ & Total pore volume $^{b}\left(\mathrm{~cm}^{3} \mathrm{~g}^{-1}\right)$ \\
\hline CP-120-0 & 55.7 & 0.44 \\
CP-120-900 & 24.9 & 0.25 \\
CP-180-0 & 46.7 & 0.30 \\
CP-180-900 & 42.9 & 0.28
\end{tabular}

${ }^{a}$ Determined by multipoint BET. ${ }^{b}$ Determined from the amount adsorbed at $P / P_{0}=0.95$.

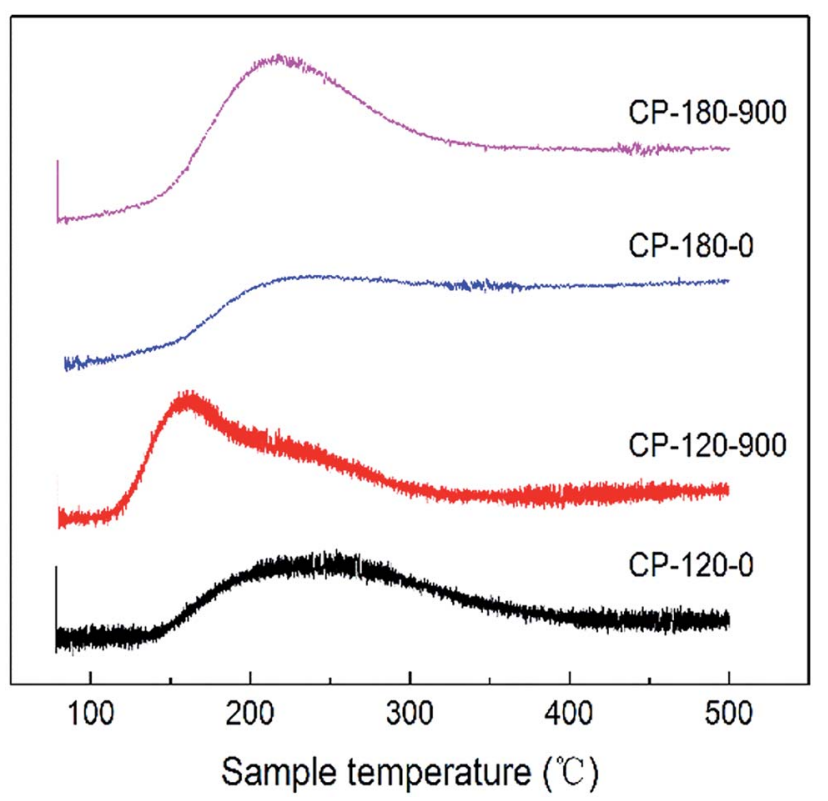

Fig. 7 The $\mathrm{NH}_{3}-\mathrm{TPD}$ curve of CP-120-0, CP-120-900, CP-180-0 and CP-180-900.

Table 2 The quantitative data of $\mathrm{NH}_{3}$-TPD for CP-120-0, CP-120900, CP-180-0 and CP-180-900

\begin{tabular}{lll}
\hline Catalysts & Peak position $\left({ }^{\circ} \mathrm{C}\right)$ & $\mathrm{NH}_{3}$ adsorption $\left(\mu \mathrm{mmol} \mathrm{g}{ }^{-1}\right)$ \\
\hline CP-120-0 & 250 & 110 \\
CP-120-900 & 160 & 184.4 \\
CP-180-0 & 200 & 96.2 \\
CP-180-900 & 210 & 190.3
\end{tabular}

Table 2. The amount of acid of CP-120-0 was $110 \mu \mathrm{mmol} \mathrm{g}^{-1}$, higher than $96.2 \mu \mathrm{mmol} \mathrm{g}^{-1}$ for CP-180-0. After calcination, the amount of acid of CP-180-900 and CP-120-900 was $190.3 \mu \mathrm{mmol}$ $\mathrm{g}^{-1}$ and $184.4 \mu \mathrm{mmol} \mathrm{g}{ }^{-1}$, respectively.

The CP catalysts with hexagonal and monoclinic structure before/after calcination (CP-120-0, CP-120-900, CP-180-0 and CP-180-900) were further characterized by XPS to analyze their surface properties and results were depicted in Fig. 8. The complex Ce XPS spectra for CP catalysts was marked for the $\mathrm{Ce}^{4+}\left(3 \mathrm{~d}^{10} 4 \mathrm{f}^{0}\right)$ and $\mathrm{Ce}^{3+}\left(3 \mathrm{~d}^{10} 4 \mathrm{f}^{1}\right)$ chemical species, which were substituted by $\nu$ and $\mu$ symbols, respectively, and was decomposed into ten components according to previous references. The binding energy (BE) of $\mathrm{Ce}^{4+}$ was considered at around $\nu_{0}=$ $881, \nu_{1}=888, v_{2}=897, \nu_{0^{\prime}}=901, \nu_{1^{\prime}}=907$ and $\nu_{2^{\prime}}=916 \mathrm{eV}$. The $\mathrm{BE}$ at around $\mu_{0}=885, \mu_{1}=882, \mu_{0^{\prime}}=904$ and $\mu_{1^{\prime}}=900 \mathrm{eV}$ was correspond with $\mathrm{Ce}^{3+}$ chemical state. The relative abundance of $\mathrm{Ce}^{4+}$ species in the CP catalysts was measured by considering the decomposed peak area of the Ce3d BE. ${ }^{\mathbf{4 9 5}}$ As shown in Fig. 8, the $\mathrm{Ce}^{4+} /\left(\mathrm{Ce}^{4+}+\mathrm{Ce}^{3+}\right)$ concentration were $39.2,47.5,37.1$ and 45.3 for CP-120-0, CP-120-900, CP-180-0 and CP-180-900, respectively. This result demonstrated calcination can improve the amount of relative abundance of $\mathrm{Ce}^{4+}$ of $\mathrm{CP}$ catalysts, no matter monoclinic structure or hexagonal structure. It was reported that $\mathrm{Ce}^{4+}$ prove the Lewis acid site, which meant 

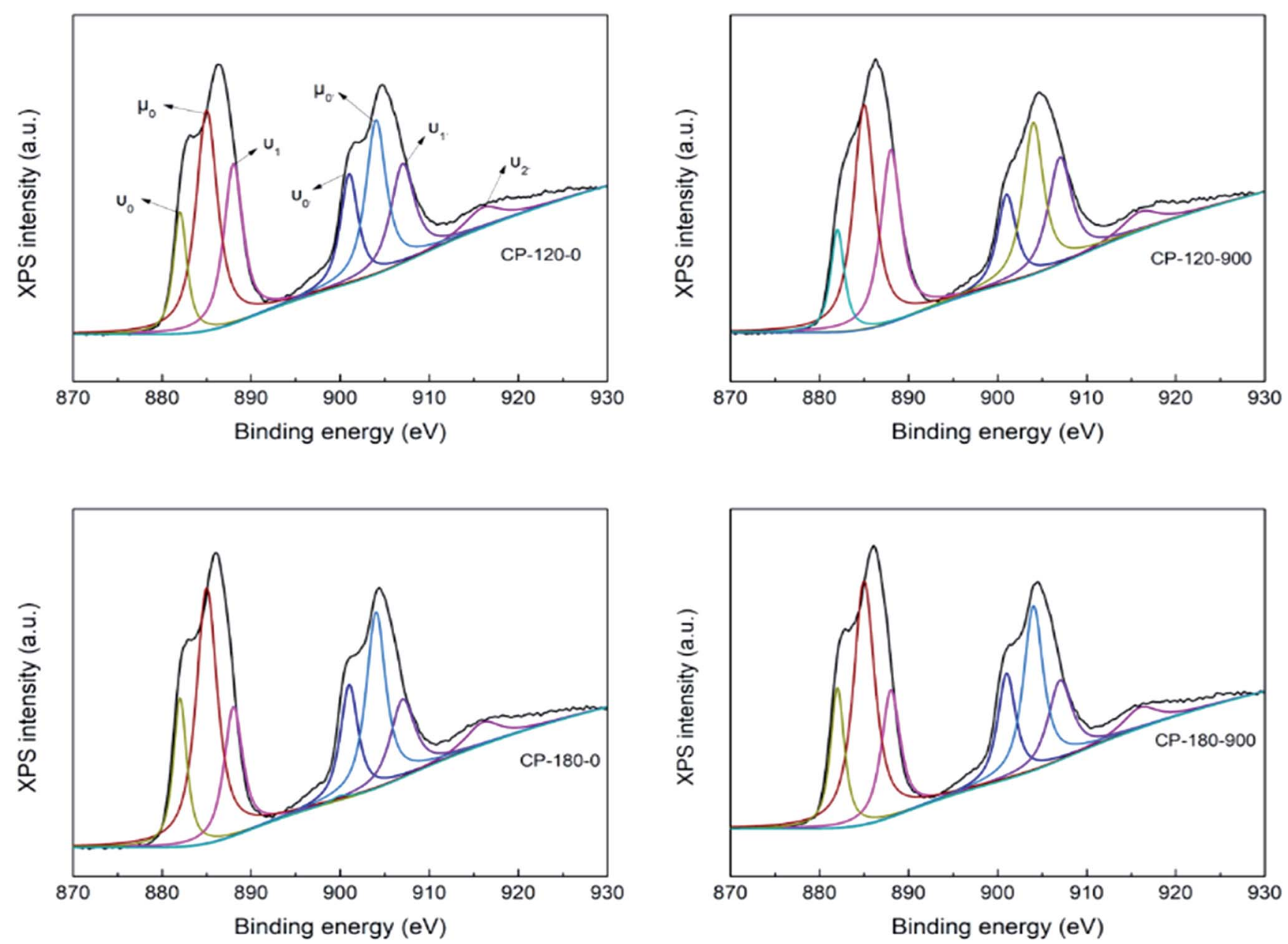

Fig. 8 The XPS of CP-120-0, CP-120-900, CP-180-0 and CP-180-900.

a change in the $\mathrm{Ce}^{4+}$ amount in the catalysts lead to a corresponding change in the Lewis acid site. ${ }^{46}$ Therefore, the $\mathrm{Ce}^{4+} /$ $\left(\mathrm{Ce}^{4+}+\mathrm{Ce}^{3+}\right)$ concentration provided the amount of acid order for CP catalysts: CP-180-900 > CP-120-900 > CP-120-0 > CP-180-0. The result of XPS also explained and was corresponding with $\mathrm{NH}_{3}$-TPD results.

The aldol condensation reaction of furfural and acetone was carried out with the molar ratio of furfural/acetone $=1 / 10$. Fig. 9 showed the catalytic performance of $\mathrm{CP}$ catalysts in aldol condensation reaction between furfural and acetone. Clearly, furfural conversion was $23.7 \%$ with $8.2 \%$ yield of FAc and $1.8 \%$ yield of $\mathrm{F}_{2} \mathrm{Ac}$ over $\mathrm{P} / \mathrm{CeO}_{2}$ at $160{ }^{\circ} \mathrm{C}$ after $3 \mathrm{~h}$, higher than $10 \%$ conversion of furfural with about $1 \%$ yield of FAc over pure $\mathrm{CeO}_{2}$ under same reaction conditions, which was attributed to the existence of a few cerium phosphate phases in the $\mathrm{P} / \mathrm{CeO}_{2}$ catalyst according to XRD results. Further, cerium phosphate prepared with hydrothermal method was used as catalysts. Furfural conversion was $89.1 \%$ with $42 \%$ yield of FAc and $17.5 \%$ yield of $\mathrm{F}_{2} \mathrm{Ac}$ over CP-120-0 and $82.3 \%$ conversion of furfural with $40.1 \%$ yield of FAc and $10.4 \%$ yield of $\mathrm{F}_{2} \mathrm{Ac}$ was achieved over CP-180-0 at $160{ }^{\circ} \mathrm{C}$ after $3 \mathrm{~h}$, much higher than $\mathrm{P} / \mathrm{CeO}_{2}$ and $\mathrm{CeO}_{2}$. These results demonstrated that cerium phosphate was an active catalyst for aldol condensation of furfural and acetone. It was worthy noting that the catalytic performance of CP-120-
0 was higher than CP-180-0, which indicated that cerium phosphate with hexagonal structure had a higher activity than monoclinic structure in the case of no calcination. Higher BET surface area, total pore volume and amount of acid were

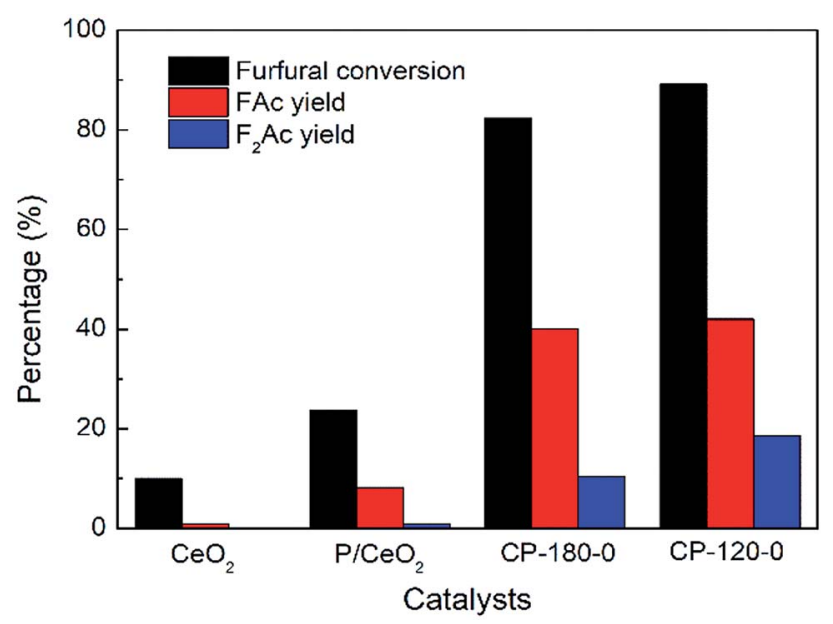

Fig. 9 The catalytic performance of $\mathrm{CeO}_{2}, \mathrm{P} / \mathrm{CeO}_{2}, \mathrm{CP}-120-0$ and CP-180-0 in aldol condensation reaction. Reaction time: $3 \mathrm{~h}$. Reaction temperature: $160^{\circ} \mathrm{C}$. 
possible reason for this difference according to BET and $\mathrm{NH}_{3}$ TPD results.

The impact of calcination temperature of $\mathrm{CP}$ catalysts on catalytic performance was studied and results were depicted in Fig. 10 and 11. As shown in Fig. 10, after calcination at $500{ }^{\circ} \mathrm{C}$, furfural conversion increased to $86.4 \%$ with $42.3 \%$ yield of FAc and $11.2 \%$ yield of $\mathrm{F}_{2} \mathrm{Ac}$ over CP-180-500 at $160{ }^{\circ} \mathrm{C}$ after $3 \mathrm{~h}$. Further increasing calcination temperature from $700{ }^{\circ} \mathrm{C}$ to $900{ }^{\circ} \mathrm{C}$, the furfural conversion increased correspondingly from 91.7\% to $96 \%$ and FAc yield as well as $\mathrm{F}_{2}$ Ac yield also increased from $47.8 \%$ to $54.3 \%$ and from $12.7 \%$ to $14.1 \%$ over CP- $180-700$ and CP-180-900 catalysts under same reaction conditions, respectively. These results clearly demonstrated that increasing calcination temperature of catalyst can improve the catalytic performance of $\mathrm{CP}$ catalysts with monoclinic structure, which was ascribed to the higher amount of acid and relative stable textural properties after catalyst was calcinated according to previous catalyst characterization.

Conversely, the catalytic performance of CP catalysts with hexagonal structure after calcination was obviously opposite with monoclinic structure. As shown in Fig. 11, the catalytic

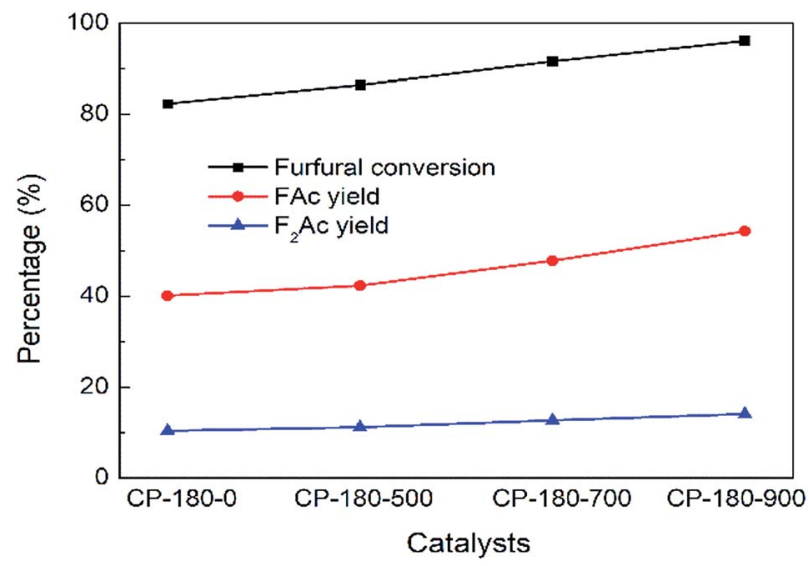

Fig. 10 The impact of calcination on catalytic performance of $\mathrm{CP}$ catalyst prepared by hydrothermal method at $180{ }^{\circ} \mathrm{C}$. Reaction time: $3 \mathrm{~h}$. Reaction temperature: $160^{\circ} \mathrm{C}$.

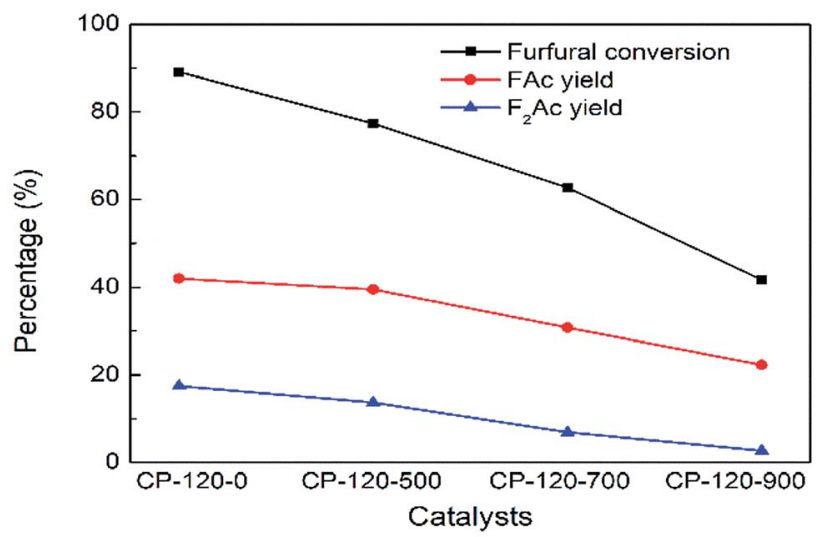

Fig. 11 The impact of calcination on catalytic performance of $\mathrm{CP}$ catalyst prepared by hydrothermal method at $120^{\circ} \mathrm{C}$. Reaction time: 3 h. Reaction temperature: $160^{\circ} \mathrm{C}$. performance of CP catalyst with hexagonal structure continuously decreased with the calcination temperature increasing. After calcination at $900{ }^{\circ} \mathrm{C}$, furfural conversion rapidly decreased to $41.7 \%$ and FAc yield and $\mathrm{F}_{2} \mathrm{Ac}$ yield decreased to $22.3 \%$ and $2.7 \%$ over $\mathrm{CP}-120-900$ at $160{ }^{\circ} \mathrm{C}$ after $3 \mathrm{~h}$, respectively. On the basis of previous catalyst characterization, different from cerium phosphate with monoclinic structure, although the amount of acid was also higher after catalyst was calcinated according to $\mathrm{NH}_{3}$-TPD, BET surface area and total pore volume decreased rapidly. It was seen in Table 1 that both BET surface area and total pore volume of CP-120-900 decreased by half but CP-180-900 hardly decreased. Therefore, relatively poor textural properties after calcination of cerium phosphate with hexagonal structure compared with monoclinic structure may be a main reason for limiting catalytic performance. These results also explained the opposite catalytic performance of two crystal structure of CP catalysts after calcination. It can be seen that cerium phosphate with monoclinic structure after calcination at $900{ }^{\circ} \mathrm{C}(\mathrm{CP}-180-900)$ have a highest activity among all these $\mathrm{CP}$ catalysts in aldol condensation reaction of furfural and acetone.

The impact of reaction time and reaction temperature were studied by conducting the aldol condensation reaction between furfural and acetone over CP-180-900 catalyst at $100-160{ }^{\circ} \mathrm{C}$ for $0.5-4 \mathrm{~h}$. The effect on furfural conversion, FAc yield and $\mathrm{F}_{2} \mathrm{Ac}$ yield were depicted in Fig. 12A, B and C, respectively. Apparently, increasing the reaction time and temperature can significantly improve the catalytic performance. For example, as shown in Fig. 12A, upon carrying out the reaction temperature at $100{ }^{\circ} \mathrm{C}$, with the reaction time increasing from $0.5 \mathrm{~h}$ to $4 \mathrm{~h}$, the furfural conversion increased from about $2 \%$ to $14.2 \%$. Keeping the reaction temperature increasing to $160^{\circ} \mathrm{C}$, with the reaction time increasing from $0.5 \mathrm{~h}$ to $4 \mathrm{~h}$, the furfural conversion increased from $53.1 \%$ to $96 \%$. The effects of reaction time and temperature on FAc yield and $\mathrm{F}_{2} \mathrm{Ac}$ yield were similar to furfural conversion. As shown in Fig. 12B and C, upon carrying out the reaction temperature at $100{ }^{\circ} \mathrm{C}$, with the reaction time increasing from $0.5 \mathrm{~h}$ to $4 \mathrm{~h}$, the FAc yield and $\mathrm{F}_{2} \mathrm{Ac}$ yield increased from $0 \%$ to $9.2 \%$ and from $0 \%$ to about $1 \%$, respectively. Keeping the reaction temperature increasing to $160{ }^{\circ} \mathrm{C}$, with the reaction time increasing from $0.5 \mathrm{~h}$ to $4 \mathrm{~h}$, the FAc yield and $\mathrm{F}_{2} \mathrm{Ac}$ yield increased from $33.7 \%$ to $54.3 \%$ and from $8.6 \%$ to $14.1 \%$. Remarkably, the improvement of catalytic performance by prolonging reaction time at low temperature $\left(100{ }^{\circ} \mathrm{C}\right)$ was not better than prolonging reaction time at high temperature $\left(160^{\circ} \mathrm{C}\right)$. This result implied that increasing reaction temperature was more influential to the catalytic performance than the reaction time.

The recyclability and regeneration of $\mathrm{CP}$ catalysts with two different structures was also studied. Fig. 13 summarized the reusability (run 2) and regeneration (run 3,4 and 5) research of CP catalyst with monoclinic structure (CP-180-900). After the first run, attempt was made to reuse the spent catalyst through just washed with acetone thoroughly and dried at $100{ }^{\circ} \mathrm{C}$. As shown in Fig. 13 (run 2), the catalytic performance of this astreated spent catalyst decreased distinctly. The furfural conversion decreased from $96 \%$ to $62.2 \%$ and the yield of FAc 

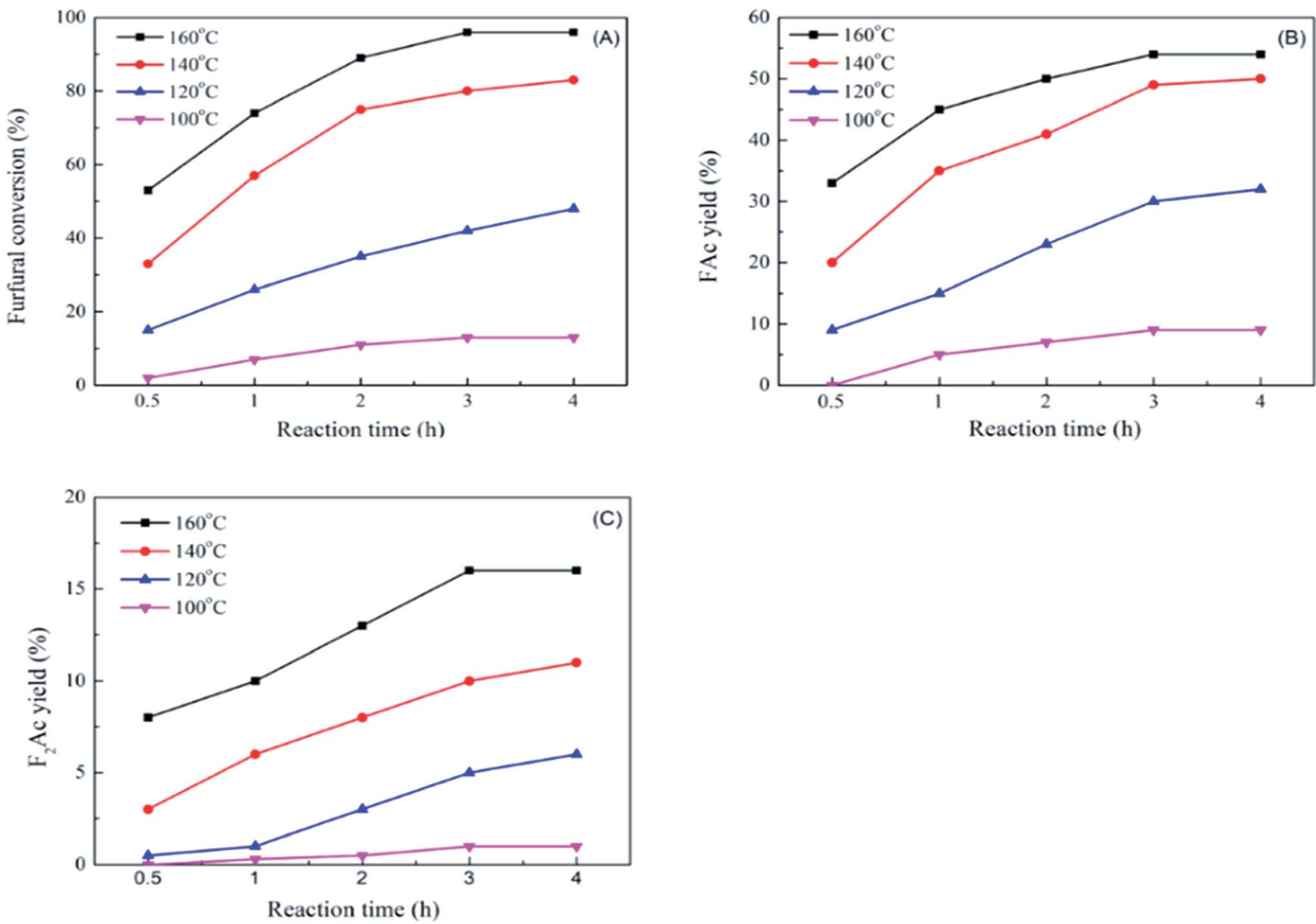

Fig. 12 The impact of reaction time and reaction temperature on furfural conversion (A), FAc yield (B) and $F_{2} A c$ yield (C) over CP-180-900.

and $\mathrm{F}_{2} \mathrm{Ac}$ decreased from $54.3 \%$ to $41.1 \%$ and $14.1 \%$ to $6.6 \%$, respectively. The result indicated that $\mathrm{CP}-180-900$ cannot be reused via only washing with acetone after reaction. The regeneration of CP-180-900 was carried out by calcination at $550{ }^{\circ} \mathrm{C}$ in air for $5 \mathrm{~h}$ after washing with acetone and drying at

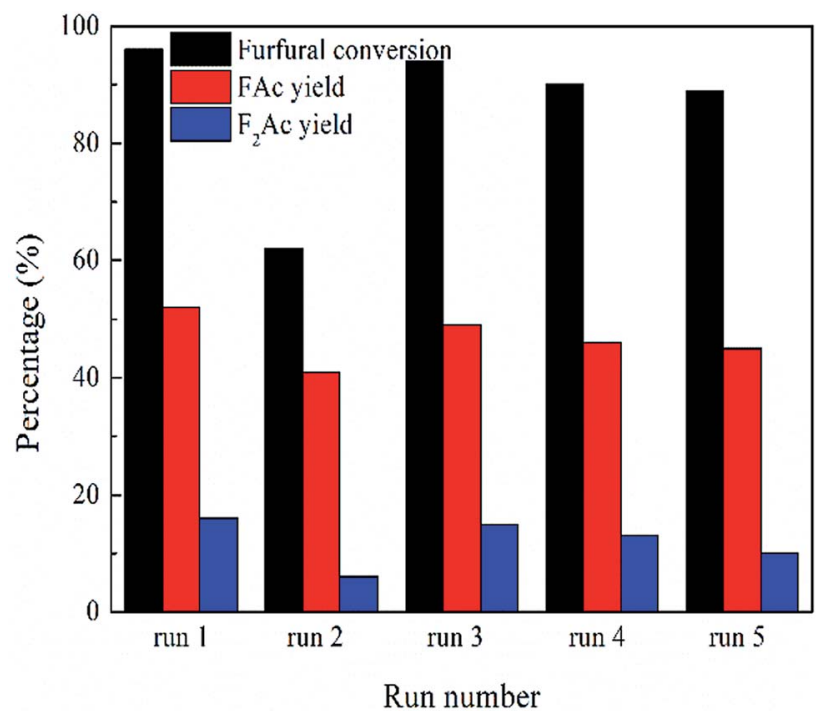

Fig. 13 The recyclability study of CP catalyst with monoclinic structure (CP-180-900). Reaction time: $3 \mathrm{~h}$. Reaction temperature: $160{ }^{\circ} \mathrm{C}$.
$100{ }^{\circ} \mathrm{C}$. The recycled $\mathrm{CP}-180-900$ showed almost the same catalytic performance compared with the first run. The furfural conversion was $94.8 \%$ with a $49.2 \%$ yield of FAc and a $13.2 \%$ yield of $\mathrm{F}_{2} \mathrm{Ac}$, respectively (run 3). The CP-180-900 was regenerated by washing, drying and calcination in air (the same way as run 3 ) in the following two runs (run 4 and run 5). Although the furfural conversion and aldol product yield continuously decreased, the catalytic performance of CP catalyst with monoclinic structure after regeneration was acceptable. However, the recyclability and regeneration of CP catalyst with hexagonal structure (CP-120-0) was unsatisfactory and results were shown in Table 3. Although the catalytic performance of the reused catalyst after calcination was higher than spent catalyst without calcination, the catalytic activity was far poor

Table 3 The recyclability of CP catalyst with hexagonal structure (CP120-0)

\begin{tabular}{llll}
\hline & & & \\
Catalysts & Furfural conversion (\%) & FAc yield (\%) & $\begin{array}{l}\mathrm{F}_{2} \mathrm{Ac} \\
\text { yield (\%) }\end{array}$ \\
\hline Fresh CP-120-0 & 89.1 & 42 & 17.5 \\
Reused CP-120-0 $^{a}$ & 59.2 & 20.5 & 9.8 \\
Reused CP-120-0 $^{b}$ & 78.4 & 36.3 & 12.1
\end{tabular}

${ }^{a}$ Washing by acetone, drying at $100{ }^{\circ} \mathrm{C}$, without calcination in air. ${ }^{b}$ Washing by acetone, drying at $100{ }^{\circ} \mathrm{C}$, with calcination in air. 


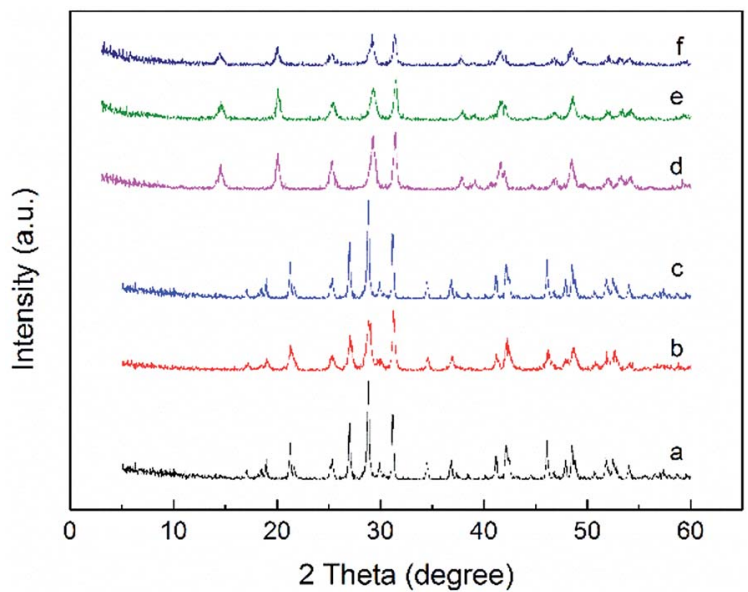

Fig. 14 The XRD pattern of reused catalysts: (a) fresh CP-180-900, (b) spent CP-190-900 without calcination, (c) spent CP-180-900 after calcination, (d) fresh CP-120-0, (e) spent CP-120-0 without calcination, $(f)$ spent $C P-120-0$ after calcination.

than the fresh catalyst. The changes of catalyst after calcination owing to its poor hydrothermal stability according to XRD results was accountable mainly for this decrease. As shown in Fig. 14, the intensity of peak of spent CP-180-900 without calcination (Fig. 14b) was weaker than fresh CP-180-900 (Fig. 14a), which was attributed to the formation of humins on the catalyst during reaction because the color of spent catalyst was brown. The XRD pattern of reused catalyst after calcination (Fig. 14c) was same with the fresh catalyst. This result revealed no significant changes happened in the crystal structure after calcination for CP-180-900. For CP-120-0, the intensity of peak of spent CP-120-0 without calcination (Fig. 14e) was also weaker than fresh CP-120-0 (Fig. 14d) because of the same reason for CP-180-900. However, the XRD pattern of reused catalyst after calcination (Fig. 14f) was also weaker than the fresh catalyst because of the part destruction of hexagonal structure of CP-120-0 during calcination. These results of XRD study of reused catalyst explained correspondingly the catalytic behavior of CP-180-900 and CP-120-0 in the recyclability test. ${ }^{51,52}$

\section{Conclusions}

The cerium phosphate with two crystal structure was used as a catalyst for aldol condensation reaction between furfural and acetone at the first time, and high furfural conversion and aldol products yield were achieved. Calcination played an important role in the catalytic activity of CP catalysts. CP catalyst with hexagonal structure which was prepared by hydrothermal method at $120^{\circ} \mathrm{C}$ and without calcination had a better catalytic behavior than $\mathrm{CP}$ catalyst with monoclinic structure but after calcination, CP catalyst with monoclinic structure showed a higher catalytic activity, which was attributed to the comprehensive impact of the change of amount of acid and textural properties with calcination. In addition, the furfural conversion slightly decreased to $89.8 \%$ with $\mathrm{FAc}$ and $\mathrm{F}_{2} \mathrm{Ac}$ yield decreasing to $45.1 \%$ and $10.5 \%$, respectively, for CP-180-900 after five runs but the furfural conversion rapidly decreased to $78.4 \%$ with FAc and $\mathrm{F}_{2} \mathrm{Ac}$ yield decreasing to $36.3 \%$ and $12.1 \%$, respectively, for CP-120-0 after only two runs. The recyclability study indicated the catalytic performance of $\mathrm{CP}$ catalyst with monoclinic structure was acceptable after five runs but CP catalyst with hexagonal structure was unsatisfactory owing to its poor hydrothermal stability.

\section{Conflicts of interest}

There are no conflicts to declare.

\section{Acknowledgements}

This study was financially supported by the National Key R\&D Program of China (No. 2018YFB1501600), "Transformational Technologies for Clean Energy and Demonstration", Strategic Priority Research Program of the Chinese Academy of Sciences, Grant No. XDA 21060101, National Natural Science Foundation of China (51676178), the Science and Technological Fund of Anhui Province for Outstanding Youth (1508085J01).

\section{Notes and references}

1 M. Stöcker, Angew. Chem., Int. Ed., 2008, 47, 9200-9211.

2 S. Zinoviev, f. Müller-Langer, P. Das, N. Bertero, P. Fornasiero, M. Kaltschmitt, G. Centi and S. Miertus, ChemSusChem, 2010, 3, 1106-1133.

3 D. Kubička, I. Kubičková and J. Čejka, Catal. Rev. Sci. Eng., 2013, 55, 1-78.

4 G. W. Huber and A. Corma, Angew. Chem., Int. Ed., 2007, 46, 7184-7201.

5 A. Bohre, B. Saha and M. M. Abu-Omar, ChemSusChem, 2015, 8, 4022-4029.

6 S. Wang, Y. Zhao, H. Lin, J. Chen, L. Zhu and Z. Luo, Green Chem., 2017, 19, 3869-3879.

7 H. Lin, Q. Xiong, Y. Zhao, J. Chen and S. Wang, AIChE J., 2017, 63, 257-265.

8 H. Lin, J. Chen, Y. Zhao and S. Wang, Energy Fuels, 2017, 31, 3929-3934.

9 B. O. de Beeck, M. Dusselier, J. Geboers, J. Holsbeek, E. Morré, S. Oswald, L. Giebeler and B. F. Sels, Energy Environ. Sci., 2015, 8, 230-240.

10 A. Bohre, S. Dutta, B. Saha and M. M. Abu-Omar, ACS Sustainable Chem. Eng., 2015, 3, 1263-1277.

11 G. W. Huber, J. N. Chheda, C. J. Barrett and J. A. Dumesic, Science, 2005, 308, 1446-1450.

12 P. A. Zapata, J. Faria, M. P. Ruiz and D. E. Resasco, Top. Catal., 2012, 55, 38-52.

13 N. Fakhfakh, P. Cognet, M. Cabassud, Y. Lucchese and M. D. d. L. Ríos, Chem. Eng. Process., 2008, 47, 349-362.

14 C. Ramirez-Barria, A. Guerrero-Ruiz, E. Castillejos-López, I. Rodriguez-Ramos, J. Durand, J. Volkman and P. Serp, RSC Adv., 2016, 6, 54293-54298.

15 C. D. Gutsche, D. Redmore, R. S. Buriks, k. Nowotny, H. Grassner and C. W. Armbruster, J. Am. Chem. Soc., 1967, 89, 1235-1245. 
16 R. M. West, Z. Y. Liu, M. Peter, C. A. Gärtner and J. A. Dumesic, J. Mol. Catal. A: Chem., 2008, 296, 18-27.

17 R. Xing, A. V. Subrahmanyam, H. Olcay, W. Qi, G. P. van Walsum, H. Pendse and G. W. Huber, Green Chem., 2010, 12, 1933-1946.

18 H. Li, Z. Xu, P. Yan and Z. C. Zhang, Green Chem., 2017, 19, 1751-1756.

19 C. J. Barrett, J. N. Chheda, G. W. Huber and J. A. Dumesic, Appl. Catal., B, 2006, 66, 111-118.

20 R. E. O'Neill, L. Vanoye, C. De Bellefon and F. Aiouache, Appl. Catal., B, 2014, 144, 46-56.

21 X. Sheng, N. Li, G. Li, W. Wang, A. Wang, Y. Cong, X. Wang and T. Zhang, Green Chem., 2016, 18, 3707-3711.

22 I. Sádaba, M. Ojeda, R. Mariscal, R. Richards and M. L. Granados, ChemPhysChem, 2012, 13, 3282-3292.

23 J. Yang, N. Li, S. Li, W. Wang, L. Li, A. Wang, X. Wang, Y. Cong and T. Zhang, Green Chem., 2014, 16, 4879-4884.

24 W. Xu, X. Liu, J. Ren, H. Liu, Y. Ma, Y. Wang and G. Lu, Microporous Mesoporous Mater., 2011, 142, 251-257.

25 M. Li, X. Xu, Y. Gong, Z. Wei, Z. Hou, H. Li and Y. Wang, Green Chem., 2014, 16, 4371-4377.

26 L. Faba, E. Díaz and S. Ordóñez, Appl. Catal., B, 2012, 113, 201-211.

27 X. Huang, Q. Zhang, T. Wang, Q. Liu, L. Ma and Q. Zhang, J. Fuel Chem. Technol., 2012, 40, 973-978.

28 W. Shen, G. A. Tompsett, K. D. Hammond, R. Xing, F. Dogan, C. P. Grey, W. C. Conner Jr, S. M. Auerbacha and G. W. Huber, Appl. Catal., A, 2011, 392, 57-68.

29 J. D. Lewis, S. Van de Vyver and Y. Román-Leshkov, Angew. Chem., Int. Ed., 2015, 54, 9835-9838.

30 O. Kikhtyanin, V. Kelbichová, D. Vitvarová, M. Kubů and D. Kubička, Catal. Today, 2014, 227, 154-162.

31 S. Van de Vyver, C. Odermatt, K. Romero, T. Prasomsri and Y. Román-Leshkov, ACS Catal., 2015, 5, 972-977.

32 Y. Wang, J. D. Lewis and Y. Román-Leshkov, ACS Catal., 2016, 6, 2739-2744.

33 O. Kikhtyanin, P. Chlubná, T. Jindrová and D. Kubička, Dalton Trans., 2014, 43, 10628-10641.

34 M. Su, W. Li, T. Zhang, H. Shen, S. Li, W. Fan and L. Ma, Catal. Sci. Technol., 2017, 7, 3555-3561.
35 G. Yan, Y. Zhang, W. Di and W. Qin, Dyes Pigm., 2018, 159, 28-34.

36 H. Liu and Z. Ma, Chin. J. Chem. Eng., 2018, 26, 109-115.

37 H. Wu, P. Jin, Y. Sun, M. Yang, C. Huang, W. Weng and H. Wan, J. Mol. Catal. A: Chem., 2016, 414, 1-8.

38 Y. You, C. Shi, H. Chang, L. Guo, L. Xu and J. Li, Mol. Catal., 2018, 453, 47-54.

39 S. Kouass, A. Fadhalaoui, M. Kahlaoui, H. Dhaouadi and F. Touati, Mater. Lett., 2018, 217, 75-78.

40 J. Shi, H. Feng, C. Qv, D. Zhao, S. Hong and N. Zhang, Appl. Catal., A, 2018, 561, 127-136.

41 Y. Zeng, Y. Wang, S. Zhang, Q. Zhong, W. Rong and X. Li, J. Colloid Interface Sci., 2018, 524, 8-15.

42 T. O. Shekunova, A. E. Baranchikov, O. S. Ivanova, L. S. Skogareva, N. P. Simonenko, Yu. A. Karavanova, V. A. Lebedev, L. P. Borilo and V. K. Ivanov, J. Non-Cryst. Solids, 2016, 447, 183-189.

43 Y. Wang, S. Wang, K. Ou, Y. Zhang, L. Bai and L. Yi, Optik, 2019, 178, 944-949.

44 D. Palma-Ramírez, M. A. Domínguez-Crespo, A. M. TorresHuerta, V. A. Escobar-Barrios, H. Dorantes-Rosales and H. Willcock, Polymer, 2018, 142, 356-374.

45 S. Kanai, I. Nagahara, Y. Kita, K. Kamata and M. Hara, Chem. Sci., 2017, 8, 3146-3153.

46 L. Wang, F. Yuan, X. Niu, C. Kang, P. Li, Z. Li and Y. Zhu, RSC Adv., 2016, 6, 40175-40184.

47 Y. Sasaki, K. Ishii and Y. Kashiwaya, J. Mater. Sci. Lett., 2001, 20, 1071-1075.

48 J. Pang, X. Li, W. Zou, C. Tang, Y. Wang and L. Dong, ChemistrySelect, 2018, 3, 12389-12395.

49 P. Maitarad, J. Han, D. Zhang, L. Shi, S. Namuangruk and T. Rungrotmongkol, J. Phys. Chem. C, 2014, 118, 9612-9620.

50 Y. Yu, B. He, Y. Liao, X. Yu, Z. Mu, Y. Xing and S. Xing, ChemElectroChem, 2018, 5, 793-798.

51 Y. Lin, S. Wu, X. Li, X. Wu, C. Yang, G. Zeng, Y. Peng, Q. Zhou and L. Li, Appl. Catal., B, 2018, 227, 557-570.

52 Y. Lin, S. Wu, C. Yang, M. Chen and X. Li, Appl. Catal., B, 2019, 245, 71-86. 